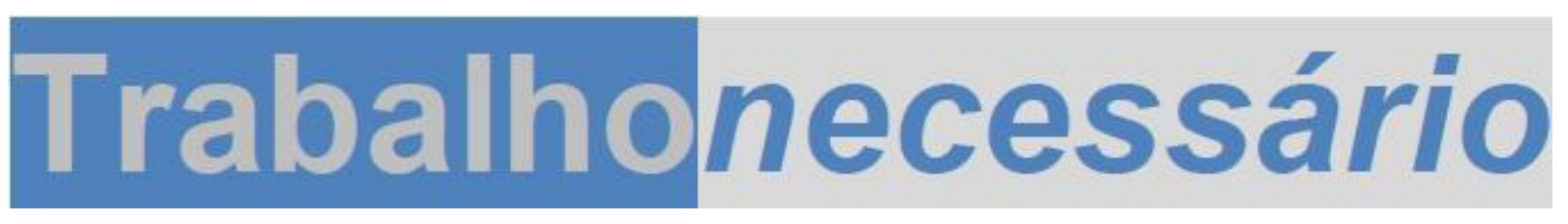

Issn: 1808 - 799X

ano 12 , no $18-2014$

\title{
A IDEIA DE CULTURA E A EXPERIÊNCIA NA FEIRA DE SÃO CRISTÓVÃO: DELINEANDO CAMINHOS
}

\author{
Rafaela De Souza Ribeiro ${ }^{1}$
}

\section{Resumo}

O artigo é parte da pesquisa de doutoramento realizada junto à tradicional Feira de São Cristóvão, intitulada: Feira de São Cristóvão e os descaminhos do traço cultural na modernidade. A proposta, inicialmente, será abordar o significado de cultura e alguns conceitos chaves subjacentes a ele a partir de uma abordagem crítica com ênfase na chamada cultura popular. As referências teóricas destacam a discussão de pensadores da chamada "nova esquerda": E.P Thompson e

Raymond Willians, a partir, principalmente, de conceitos chaves de suas obras, como cultura e experiência. A interface da discussão desses autores com a Feira de São Cristóvão parece delinear uma gama de possibilidades para pensar a experiência dos trabalhadores e sua participação enquanto representantes da cultura popular nordestina. Nessa experiência, a cultura assume um papel central, porém a partir de pontos de vistas diferenciados, corroborando para a formação de um espaço de conflito e resistência. O texto contempla apontamentos teóricos relevantes para pensar o objeto em questão, a cultura e a feira nordestina, que serão, posteriormente, aprofundados na tese.

Palavras-chave: Feira de São Cristóvão; Cultura; Cultura Popular.

\footnotetext{
${ }^{1}$ Professora Assistente da Escola de Serviço Social da Universidade Federal do Estado do Rio de Janeiro, Unirio e doutoranda do Programa de Pós-graduação em Serviço Social da Universidade do Estado do Rio de Janeiro, UERJ. Email: ribeiro.rafaela@gmail.com
}

TrabalhoNecessário - www.uff.br/trabalhonecessario; Ano 12, № 18/2014. 


\title{
Trabalhonecessário
}

Issn: 1808 - 799X

ano 12, no $18-2014$

\begin{abstract}
The article is part of the doctoral research carried out with the traditional São Cristóvão Fair, entitled : São Cristóvão fair and waywardness of the cultural trait in modernity . Initially proposal will approach the significance of culture and some key concepts underlying it from a critical approach with emphasis on the so-called popular culture. The theoretical results highlight the discussion of thinkers called the "New Left": E.P Thompson and Raymond Williams, from mainly the key concepts of his, such as culture and experience. The interface of the discussion of these authors with the São Cristóvão fair seems to outline a range of possibilities to think the experience of the working class and their representation in popular culture Northeast. In this experience, culture plays a central role, but from different points of view, corroborating the formation of an area of conflict and resistance. From a critical analysis, the text proposes few theorists to think the object in question, the culture and the Northeast Fair, which will be detailed later in the completely thesis.
\end{abstract}

Keywords: São Cristóvão fair ; Culture; Popular Culture

\section{Apresentação}

O objetivo deste artigo é realizar alguns apontamentos acerca da definição de cultura, enquanto categoria teórica fundamental, para dar seguimento aos estudos que serão aprofundados na tese de doutoramento intitulada: Feira de São Cristóvão e os descaminhos do Traço cultural na modernidade.

A proposta inicialmente será abordar o significado de cultura e alguns conceitos chaves subjacentes a ele, a partir de uma abordagem crítica e, enfatizando, o que podemos chamar de cultura popular. Para isso, tomarei como

TrabalhoNecessário - www.uff.br/trabalhonecessario; Ano 12, № 18/2014. 


\section{Trabalhonecessário}

Issn: 1808 - 799X

ano 12, no $18-2014$

referência a discussão de teóricos da chamada "nova esquerda": E.P Thompson ${ }^{2}$ e Raymond Willians ${ }^{3}$, autores que claramente recuperam o peso histórico que tem conferido conteúdo às diversas formas assumidas por tal significado.

A interface da discussão desses autores com a Feira de São Cristóvão parece delinear uma gama de possibilidades para pensar a experiência da classe trabalhadora e o cotidiano de vida e trabalho dos feirantes, artistas, músicos e artesãos. Nesse sentido, a cultura assume um papel central, porém a partir de experiências diferenciadas, corroborando para a formação de um espaço de conflito e resistência.

Assim, não pretendo aqui esgotar a discussão, mas levantar questionamentos a fim de possibilitar algumas reflexões teóricas em torno do objeto de pesquisa e, com isso, abrir caminhos para investigações futuras.

\section{Resgatando a noção de cultura e sua interface com a feira nordestina}

Dentre os diversos mercados e feiras populares na cidade, a Feira de São Cristóvão chamou-me atenção pela importância que vem conquistando no cenário urbano, e principalmente por delinear características próprias, como a de representar uma cultura específica, a nordestina, num espaço tão diferenciado como a cidade do Rio de Janeiro.

\footnotetext{
2 Historiador inglês, Edward Thompson é considerado, junto a Raymond Williams e Richard Hoggart, fundador de uma nova disciplina, os estudos culturais. Como eles, Thompson também participou do projeto de educação de trabalhadores. Ex-membro do Partido Comunista, ajudou a formar o movimento da Nova Esquerda, preocupado em romper com o direcionamento político definido pelo partido, em Moscou. (Revista Cantareira, 8a edição online-UFF). http://www.historia.uff.br/cantareira/novacantareira/artigos/edicao8/artigo02.pdf

${ }^{3}$ Raymond Williams, intelectual de tradição marxista foi membro do Partido Comunista na GrãBretanha, e após romper com o partido, ingressou como membro da corrente britânica conhecida como "nova esquerda", onde revisitando o conceito de cultura no interior da tradição marxista, fundou uma nova disciplina: o materialismo cultural (Idem).
}

TrabalhoNecessário - www.uff.br/trabalhonecessario; Ano 12, № 18/2014. 


\section{Trabalhonecessário}

Issn: 1808 - 799X

ano 12, no $18-2014$

Alguns estudos sobre a Feira revelam uma disputa pelo espaço ocupado pelos feirantes, o pavilhão de São Cristóvão, e seus arredores. Ao longo de sua história, foi alvo de inúmeras disputas políticas e ideológicas: a constante investida dos moradores do bairro, que se sentiam "inseguros e incomodados" com a suposta "desordem" causada pela antiga feira (que inicialmente não contava com nenhum tipo de regulamentação formal do espaço); posteriormente, as repressões policiais; e em seguida, por parte dos empresários da construção civil, já que ocupava um espaço "potencialmente valioso" para as investidas do capital: localização central, já especulada pelo crescente mercado imobiliário.

Contudo, apesar de explorem o significado do espaço e a representação social da identidade do nordestino, grande parte desses estudos relega ao segundo plano ou desconsidera, o conjunto de práticas cotidianas e a experiência compartilhada por esses sujeitos, traduzidas aqui, no que podemos chamar de cultura popular.

Nesse sentido, caberá aqui nesse artigo um pouco do desvendamento do significado e do lugar da cultura e da cultura popular para compreensão do objeto de pesquisa. Essa iniciativa me parece urgente, na medida em que a cultura popular representada pelos feirantes nordestinos, por meio de um amplo material que vai da literatura de cordel à comida e música típicas, assume no atual contexto histórico, novos significados tanto para os feirantes, como para os organizadores da feira, representantes do poder público e transeuntes.

Todo histórico da feira nordestina, desde sua implantação, em meados da década de 1940, até os dias atuais, foi perpassado por lutas quase sempre invisíveis que acompanharam a história da sociedade brasileira.

Inicialmente, quando se afirmou como comércio popular de produtos típicos, foi travada forte repressão por parte da polícia, em seguida, foi alvo da

TrabalhoNecessário - www.uff.br/trabalhonecessario; Ano 12, № 18/2014. 


\section{Trabalhonecessário}

Issn: 1808 - 799X

ano 12, no $18-2014$

política de limpeza urbana da prefeitura do Rio de Janeiro, e finalmente chegado os anos 2000, passou por uma requalificação em sua forma e em seu conteúdo, e ganhou "ares de shopping Center" passando a funcionar no interior do Pavilhão de São Cristóvão e gerenciada pela Prefeitura do Rio de Janeiro. Nesse momento, já incluída no projeto de reforma urbana, fortaleceu a construção de símbolos urbanos para pôr em prática os ideários do Plano Estratégico das Cidades.

Nesse momento, no ano de 2003, sob o comando do Prefeito César Maia, a Feira passou a integrar o projeto intitulado "Pentágono do Milênio" e foi reinaugurada com o nome de Centro Luiz Gonzaga de Tradições Nordestinas.

Esse projeto estava incluído nos 'sistemas de ações' correspondentes às políticas urbanas desenvolvidas para a cidade do Rio de Janeiro, no período de 1993 a 2008, que fortaleciam o planejamento estratégico da cidade e o empresarialismo urbano. Juntamente com o Centro Luiz Gonzaga de Tradições Nordestinas em São Cristóvão, estavam: a Cidade do Samba, na Gamboa, a Cidade da Música, na Barra da Tijuca, o Museu Guggenheim, no Píer Mauá, e o Estádio Olímpico João Havelange, no Engenho de Dentro (RIBEIRO, 2010).

Assim, a Feira articulou-se dinamicamente ao longo do tempo com diversas espacialidades, temporalidades e instituições, sendo permeada por relações conflituosas, e, nesse sentido, integrando e ao mesmo tempo desagregando os atores que dela participam. Essa relação dialética analisada por alguns estudiosos dessa cultura demonstra, portanto, que não se trata de uma forma de mercado ou feira popular tradicional, onde se comercializam produtos regionais e/ou alimentícios de modo geral. A Feira de São Cristóvão foi criada a partir de objetivos diferenciados, que apesar de revelar também um caráter da troca, tem a peculiaridade da cultura que representa, o que justifica a sua permanência.

TrabalhoNecessário - www.uff.br/trabalhonecessario; Ano 12, № 18/2014. 


\section{Trabalhonecessário}

Issn: 1808 - 799X

ano 12, no $18-2014$

Nessa disputa, entre permanecer no espaço e lutar pela sobrevivência através da arte enquanto trabalho, é que se encaixa toda trajetória desses sujeitos: feirantes, nordestinos, migrantes e trabalhadores. Grande parte vendendo sua mercadoria e sua cultura, ou sua cultura-mercadoria ou sua cultura mercantilizada.

O trabalho, a arte e a cultura são faces da mesma moeda, que para muitos desses sujeitos se traduzem num malabarismo diário ou num teatro mistificador do valor-trabalho com um fim bastante claro: a reprodução.

A arte em si, e aqui não me refiro à alta cultura, mas sim à cultura popular, sofre o rebatimento de novas necessidades impostas pelo capital, comprometendo a liberdade e as diversas formas de um determinado grupo expressar sua cultura, para incentivar a produção de necessidades imediatas e utilitárias que visam a reprodução do próprio sistema. Isso revela ainda a questão da indústria cultural, que cria uma necessidade de consumo em massa de maneira indiscriminada, onde a festa, a dança e a música dão lugar a um espetáculo comercial.

$\mathrm{Na}$ realidade, conforme destaca Canclini (1983), numa estratégia de mercado, os produtos do povo ganham destaque de alguma maneira, mas não quem os produzem, valorizados apenas pelo lucro que geram. É como se o artesanato, as festas, as crenças "tradicionais", fizessem parte de uma sociedade pré-capitalista. Entendemos que a ideia de tradição não deve estar relacionada apenas ao passado em oposição ao novo, mesmo sendo produto de uma história recente, mas se impõe também como um modo se ser. Em contrapartida, a indústria cultural reforça essa ideia de modernidade enquanto a chegada do novo, o que numa análise superficial, equaliza os dois termos, colocando em escala oposta a ideia de cultura.

TrabalhoNecessário - www.uff.br/trabalhonecessario; Ano 12, № 18/2014. 


\section{Trabalhonecessário}

Issn: 1808 - 799X

ano 12, no $18-2014$

Assim, tomadas unilateralmente a partir de uma visão mercadológica, a cultura nordestina parece representar apenas a lembrança de um passado recente, cujas formas de viver e se reproduzir são consideradas ultrapassadas e, portanto, devem ser abolidas. No que se refere à feira, esse parece ser um dilema cotidiano vivido por alguns de seus representantes que buscam o resgate do popular, da cultura e da tradição, disputando inclusive, a permanência em seu lugar de origem.

É importante lembrar, que a feira é iniciada com um ideal bastante claro, o de troca de mercadorias, especialmente alimentos, trazidas do nordeste. Essa troca era realizada pelos migrantes que aqui chegavam em busca de trabalho e que foram se acomodando nos arredores do bairro de São Cristóvão. Assim, a forma inicial da feira nordestina representava para seus criadores a busca pelo encontro do lugar de origem e pela marca do passado que deixaram para trás.

Entende-se, pois, porque em 1945 quando a feira é instalada no bairro, os migrantes são absorvidos por dentro da cidade do Rio de Janeiro no setor de serviços, mais especificamente, na construção civil, usando a feira como lugar de complementação de renda e como "plataforma" da defesa da tradição nordestina.

Nesse sentido, pode-se dizer que a relação da eira com o bairro não se explica pelo ofício dos feirantes ou pela forma de comércio que eles desenvolvem; ao contrário ela é percebida pelos agentes externos, tanto econômicos como políticos, como força estranha que era preciso controlar. Diante disso, é no registro da cultura que a feira mobiliza alguns moradores da cidade do Rio de Janeiro, sobretudo os nordestinos e os agentes políticos e econômicos com os quais ela é obrigada a se relacionar, para resistir.

Mas, longe de permanecer numa visão romântica dessa trajetória, é importante ressaltar, que hoje, o perfil dos sujeitos que compõem esse novo

TrabalhoNecessário - www.uff.br/trabalhonecessario; Ano 12, № 18/2014. 


\section{Trabalhonecessário}

Issn: 1808 - 799X

ano 12, no $18-2014$

cenário, é bastante heterogêneo, portanto, os objetivos da feira e tudo que subjaz a ela, passam por uma grande mudança.

Hoje, grande parte dos trabalhadores, que eram donos de barracas, está empregada em grandes restaurantes, ou ainda permanecem com seus pequenos negócios vendendo alimentos e outros produtos. Também permanecem os artistas, músicos e cordelistas. $O$ que há de novo são os grandes estabelecimentos gerenciados por empresários do ramo alimentício e do vestuário. As barracas maiores, que já existiam antes e eram as mais frequentadas, conseguiram apoio dos idealizadores do Centro de Tradições e viraram restaurantes renomados.

Os espaços em que se instalaram os antigos feirantes dentro do pavilhão foram financiados pela prefeitura e pagos por eles próprios, com isso, muitos ficaram de fora por não poderem arcar com tal custo.

Vale lembrar, que as lojas centrais e, consequentemente mais frequentadas, são as de comidas típicas, de propriedade de algumas personalidades da feira, como de um antigo presidente da associação dos feirantes e ex-representantes de cooperativas. As lojas apresentam estruturas modernas e são em geral melhor localizadas, próximas aos palcos onde ocorrem os shows de forró.

Nos espaços periféricos estão os vendedores de especiarias, mini açougues, lojas de discos, utensílios domésticos, roupas, e bares menores com uma característica peculiar, as máquinas de videokê, que vira a diversão principal nesses "setores mais segregados".

Diante de tal reconfiguração estão expressos resquícios de resistência e de luta pela cultura popular e de reformas que buscam a garantia de um espaço de venda de mercadorias aleatórias.

TrabalhoNecessário - www.uff.br/trabalhonecessario; Ano 12, № 18/2014. 


\section{Trabalhonecessário}

Issn: 1808 - 799X

ano 12, no $18-2014$

Assim parece profícuo sinalizar que para dar seguimento ao estudo do cotidiano dos trabalhadores e dos novos contornos assumidos pela feira de São Cristóvão, atual Centro Municipal Luiz Gonzaga de Tradições Nordestinas, aponta-se para necessidade de aprofundar a noção de cultura- a partir da experiência desses sujeitos, do seu lugar no mundo, e das relações sociais por eles compartilhadas. Enquanto categoria teórica, qual o lugar da cultura? Como ganha contornos relevantes para esse estudo?

\section{A ideia de cultura na "nova esquerda": encontrando caminhos}

Atualmente, a noção de cultura abre espaço para diferentes abordagens no âmbito das ciências sociais e da teoria social crítica, e, toda trajetória acerca desse significado, passa por contribuições diversas, dos idealistas aos marxistas até os pós-modernos.

Raymond Williams, além de questionar a noção idealista que previa uma separação entre cultura e vida material, atacou o pensamento materialista mecanicista pelo fato de este, tentando criticar os idealistas, reproduzir essa mesma concepção de campos separados ${ }^{4}$. Retomou os escritos de Marx e dos marxistas, que não teriam aprofundado a ênfase no processo social material ao se analisar a cultura. Para isto, levantou as ideias de língua, literatura e ideologia,

\footnotetext{
${ }^{4}$ No que se referem a uma sociologia da cultura, duas posições se configuraram como primordiais em contraposição aos outros estilos, para contribuição de um estudo intensivo das relações entre as atividades "culturais" e as demais formas de vida social: "a dos idealistas- que enfatizava o espírito formador de um modo de vida global, manifesto por todo um âmbito das atividades sociais, porém mais evidente em atividades "especificamente culturais"- uma certa linguagem, estilos de arte, tipos de trabalho intelectual ; e a dos materialistas- que enfatizava uma ordem social global no seio da qual uma cultura específica, quanto a estilos de arte e tipos de trabalho intelectual, é considerada produto direto ou indireto de uma ordem primordialmente constituída por outras atividades sociais" (WILLIAMS,1992, p.12).
}

TrabalhoNecessário - www.uff.br/trabalhonecessario; Ano 12, № 18/2014. 


\section{Trabalhonecessário}

Issn: 1808 - 799X

ano 12, no $18-2014$

afirmando que só se pode pensar o que é cultura a partir da reflexão conjunta com esses outros conceitos.

As mudanças no reordenamento da sociedade, a partir da organização de um modo de produção específico, o modo de produção capitalista, não poderia a partir dessa ótica, compreender transformações nos diferentes âmbitos, de forma compartimentada, ou seja, na política, na economia e na cultura, todo o processo ocorre de maneira inter-relacionada nessas diferentes esferas. Essa é na realidade, a visão dos autores que compõem a chamada Nova Esquerda. Essa ideia ajuda a compreender melhor como as transformações no espaço do Centro de Tradições vêm a reboque da história social e econômica do lugar, e como isso rebate na forma de viver e trabalhar dos sujeitos ${ }^{5}$.

$O$ conceito de cultura deve ser investigado pelos diferentes significados que incorporou até se tornar um campo de estudo autônomo no século XX, sem deixar de retomar, para isso, alguns conceitos chaves (que estão relacionados às tentativas de explicação para tais mudanças) com o objetivo de resgatar o lugar do popular e das massas nesse processo.

Assim, para os estudos contemporâneos, trabalhar na chave da cultura, significa realizar escolhas teóricas capazes de romper com visões românticas e elitistas, assim como apontar para uma renovação de conceitos a fim de recompor a ideia de cultura sem perder de vista as contradições que lhes são inerentes. Serão muitas as tentativas de retorno aos velhos conceitos, que se reatualizam

\footnotetext{
${ }^{5} \mathrm{O}$ bairro de São Cristóvão recebeu grande número de migrantes pelo perfil industrial que conservava até o início do século passado. Mas com a decadência desse perfil, passou a abrigar apenas pequenas fábricas, deixando de ser um bairro operário. Com a grande especulação do espaço passa a ser alvo do capital financeiro, e alguns complexos, como a Quinta da Boa Vista, a Feira de São Cristóvão, o Museu Nacional, ou seja, símbolos do tradicional bairro ganham reformas para melhor atender às necessidades da cidade.
}

TrabalhoNecessário - www.uff.br/trabalhonecessario; Ano 12, № 18/2014. 


\section{Trabalhonecessário}

Issn: 1808 - 799X

ano 12, no $18-2014$

nesse complexo, como forma de garantir poder e subjugar o que não se adéqua à ideologia da cultura dominante.

Para Williams (2011) configura-se nesse sentido, uma dificuldade, onde - a compatibilidade de uma especialização crescente com uma cultura genuinamente comum - só se resolverá num contexto de comunidade das condições materiais da sociedade e através do processo democrático em sua plenitude.

É importante destacar nesse sentido, que o conceito de cultura a que me refiro, não desconsidera o lugar da política para uma leitura mais completa da realidade. Não se tem aqui o objetivo de exaltar essa noção com um propósito pós-modernista onde tudo abrange e pouco tem a dizer sobre política, economia e cultura.

Ao contrário, toda a experiência e modo de vida dos nordestinos da feira ganham novos contornos decorrentes direta e indiretamente de mudanças na vida política, econômica e social presentes na relação global-local, estejam eles conscientes ou não desse processo.

As análises de Thompson completam essa visão, quando, por exemplo, ao resgatar a experiência das classes populares em seu cotidiano, apontam para formas de investigação de vida e de trabalho desde momentos históricos considerados como pré-industriais, onde mesmo antes de uma perspectiva definida de classe, esse conjunto de experiências condensava uma forma de organização e, portanto, de cultura própria ao período histórico:

estou convencido de que devo abandonar o conceito curiosamente estático de "base" e "superestrutura", pelo qual, na tradição marxista dominante, a "base" vem identificada com o "econômico", afirmando uma propriedade heurística das necessidades e comportamentos econômicos diante de normas e sistemas de valores. Numa só voz, podemos afirmar que o "ser social" determina a "consciência social" (uma assertiva que ainda pede exame e qualificação escrupulosos). Enquanto isso, deixamos aberta para uma investigação comum, a questão de sabermos quanto é significativo, em qualquer sociedade, descrever o "ser social" independentemente tanto das normas e estruturas

TrabalhoNecessário - www.uff.br/trabalhonecessario; Ano 12, № 18/2014. 


\section{Trabalhonecessário}

Issn: 1808 - 799X

ano 12, no $18-2014$

cognitivas primárias quanto das necessidades materiais em cujo entorno se organiza a existência (THOMPSON, 2001, p.254).

Para Thompson (2010), só podemos sustentar essa assertiva, se descartarmos a noção de econômico em seu sentido contemporâneo limitado e retornarmos à plena acepção de um modo de produção. Nessa direção, o autor reforça que as versões reducionistas e economicistas do marxismo estão distantes do pensamento de Marx- onde o importante conceito de modo de produção, com todos os seus correspondentes conceitos, normas e formas de poder vem ser tomados como um todo e confundidos com a acepção estreita de "econômico".

Assim, conclui que "quando procedemos ao exame da sociedade real, seja qual for, rapidamente descobrimos (ou pelo menos deveríamos descobrir) a inutilidade de se esboçar uma divisão assim, entre base e superestrutura" (2001, p.255). Nesse caso, a cultura passa ser considerada um reflexo secundário das forças hegemônicas produzidas pela base, não havendo uma relação de complementaridade entre os aspectos econômicos, cultural, políticos, cujas influências são recíprocas e revelam um movimento dialético, ao mesmo tempo de conformismo e resistência.

Em $A$ formação da classe operária inglesa, a partir do resgate do conceito de experiência, Thompson visando superar o suposto determinismo, onde a superestrutura é sempre determina pela base (determinante), enfatiza a formação da consciência da classe operária como um processo, e, leva em consideração tanto o impacto da formação econômica como o da formação cultural, pela própria experiência dos operários.

TrabalhoNecessário - www.uff.br/trabalhonecessario; Ano 12, № 18/2014. 


\section{Trabalhonecessário}

Issn: 1808 - 799X

ano 12, no $18-2014$

Para o autor, nenhum modelo conseguiria proporcionar o que deveria ser a "verdadeira" formação de classe em uma determinada etapa do processo histórico, pois as classes acontecem, 'fazem-se':

a transformação histórica acontece não por uma dada "base" ter dado vida a uma "superestrutura" correspondente, mas pelo fato de as alterações nas relações produtivas serem vivenciadas na vida social e cultural, de repercutirem nas ideias e valores humanos e de serem questionados nas ações, escolhas e crenças humanas (THOMPSON, 2010, p.263).

Mattos (2007) destaca que Thompson manifesta como princípio de análise a conexão entre as relações de produção e a consciência de classe, através da mediação da experiência, o autor reforça seu estudo no polo da consciência, bem como seus condicionantes e constituintes em termos culturais e de valores morais. Nesse sentido, para o autor, sua obra procura resgatar a questão da determinação, defendendo que "há uma simultaneidade da manifestação de relações produtivas particulares em todos os sistemas e áreas da vida social" (2007, p.46).

Em uma passagem de As peculiaridades dos Ingleses e outros artigos, Thompson reforça a falência dos conceitos base e superestrutura, e esclarece:

a boa sociedade pode ser simplesmente criada (tal como na teoria stalinista) a partir da construção de uma base industrial pesada; isso dado, uma superestrutura cultural irá, de algum modo, construir-se sozinha. Numa variante mais recente, a althusseriana, com ênfase na "autonomia relativa" e na "determinação em última instância", os problemas do materialismo histórico e cultural são deixados sem solução, assim como embaralhados e elididos (THOMPSON, 2001, p.256).

$\mathrm{Na}$ mesma direção, Williams sinaliza a importância de resgatar esses conceitos a fim de realizar uma análise mais cuidadosa, onde a partir do próprio Marx, dando ênfase nas atividades produtivas em relações estruturais específicas

TrabalhoNecessário - www.uff.br/trabalhonecessario; Ano 12, № 18/2014. 


\section{Trabalhonecessário}

Issn: 1808 - 799X

ano 12, no $18-2014$

(que constitui o alicerce de todas as outras atividades), refere que essa base não é estática, e pode sofrer constantes variações na dinâmica dessas forças. Logo, é um processo e não um estado. Resgata três pontos importantes:

1) A "determinação"- para a fixação de limites e o exercício de pressões , afastando-a de um conteúdo previsto, prefigurado e controlado.

2) A "superestrutura"- em direção a uma gama de práticas culturais relacionadas, afastando-a de um conteúdo refletido, reproduzido ou especificamente dependente;

3) A "base"- que é compreendida no marxismo enquanto forças produtivasafastando-a da noção de uma abstração econômica e tecnológica fixa e aproximando-a das atividades específicas de homens em relações sociais e econômicas reais, atividades que contém contradições e variações fundamentais e, portanto, encontram-se sempre num estado de processo dinâmico (WILLIANS, 2011a, p.47).

No marxismo vulgar esses conceitos foram empregados de forma a desconsiderar a dinâmica das classes subalternas, engessando-a, isso rebate no campo da cultura, uma vez que a enquadra na superestrutura, sempre determinada pela base. Isso implica de certa forma uma necessidade de avançar para o estudo de outros conceitos subjacentes a esse, como é o caso da totalidade, e da hegemonia ${ }^{6}$, que de certo, não daríamos conta neste texto. Porém, vale destacar a crença do autor, que podemos usar corretamente a noção

\footnotetext{
${ }^{6}$ Aqui, o conceito de hegemonia tem influencia dos estudos de Gramsci, onde "a hegemonia pressupõe algo verdadeiramente total, não apenas secundário ou superestrutural, como no sentido fraco de ideologia, mas que é vivido em tal profundidade, que satura a sociedade a tal ponto e que, constitui mesmo a substância e o limite do senso comum para muitas pessoas sob sua influência, de maneira que corresponde à realidade da experiência social muito mais nitidamente do que qualquer noção derivada da fórmula de base e superestrutura" (WILLIANS, 2011a, p.51).
}

TrabalhoNecessário - www.uff.br/trabalhonecessario; Ano 12, № 18/2014. 


\section{Trabalhonecessário}

Issn: 1808 - 799X

ano 12, no $18-2014$

de totalidade apenas quando combinada com a de hegemonia, por que cada sociedade tem uma organização e uma cultura específica.

Tais conceitos podem delinear alguns caminhos para pensar a Feira de São Cristóvão, na medida em que a cultura popular pode ser considerada como um fator chave para apontar a forma de inserção dos sujeitos diante do processo de disputa travado naquele espaço.

Assim, vale lembrar, que essas disputas, podem revelar vestígios de resistência talvez como reflexo da forma de organização dos sujeitos num movimento de contestação da ordem imposta e da necessidade de permanecer no lugar de origem, sob a mesma alegação das forças hegemônicas (na figura do poder público, dos empresários e comerciantes mais representativos), a bandeira da cultura.

Dialeticamente, esses sujeitos são representantes de uma cultura popular que vem sendo utilizada para "venda da imagem do lugar", e ao mesmo tempo, que guarda fortes traços de sua identidade e origem também utilizada para resistir às várias formas de massificação. É claro, que isso não se dá no interior da Feira, de forma homogênea, e provoca entre os próprios feirantes um sentimento de disputa, configurando muitas vezes um ambiente hostil entre eles ${ }^{7}$.

A experiência desses sujeitos se traduz dinamicamente na luta pela sobrevivência e pela manutenção de uma cultura já estigmatizada e quase esquecida. Dialeticamente, como já mencionado, a economia local do bairro, é movimentada pela bandeira da cultura nordestina que gera movimentação turística e venda de uma imagem fictícia do nordeste. Essa mistura revela um fetiche mascarado pela suposta tradição e memória que afirmam representar. Assim, a complexidade das relações, só pode ser observada quando

7 Sobre a formação de diferentes grupos, internamente na Feira de São Cristóvão, ver Ribeiro (2010).

TrabalhoNecessário - www.uff.br/trabalhonecessario; Ano 12, №18/2014. 


\section{Trabalhonecessário}

Issn: 1808 - 799X

ano 12, no $18-2014$

direcionamos a investigação para o desvendamento do real através de uma visão crítica, que comporte ultrapassar as armadilhas que esse cenário nos impõe.

Para Williams (1992), a cultura, nas sociedades modernas capitalistas, está organizada em uma rede complexa de atividades, relações e instituições em que não cabe isolar o estudo e supor, por exemplo, na teoria e na prática, "um lado econômico da vida", "um lado espiritual", "um de lazer" etc. Assim, os estudos culturais hoje, deixam de ver não apenas que nem todas as questões políticas são culturais, mas que nem todas as diferenças culturais são políticas.

Nesse sentido, há de se atentar para o incentivo à produção de subculturas que pode igualmente fortalecer o poder político dominante com sua fragmentação e capacidade ainda maior de alienação, produzindo assim, uma grande massa de adversários desunidos. Para o pensamento pós-moderno, quanto menor e descontínuo for, melhor.

Com a inauguração do Centro de Tradições, a dinâmica mais homogeneizada do lugar acaba diluindo e segregando os sujeitos, cuja organicidade será orientada pelo mercado para a venda da cultura.

$\mathrm{Na}$ concepção de Williams, uma teoria da cultura só seria eficaz se partisse, em termos humanos, das relações entre os elementos de um sistema geral de vida, isto é, da forma pela qual os homens se movem no mundo para viver. Tendo constatado que o termo cultura originou-se da própria vida, na qual estavam imersos os autores que ele acuradamente estudou em específico, entende que é com ela que devemos nos envolver para compreender nosso presente e perspectivar o futuro ( WILLIANS, 1992, p.57).

A ideia de cultura tomada pelo autor está baseada na narrativa onde modo de vida e produto artístico não se excluem, porque em ambos o valor atribuído está no significado coletivo.

TrabalhoNecessário - www.uff.br/trabalhonecessario; Ano 12, № 18/2014. 


\title{
Trabalhonecessário
}

Issn: 1808 - 799X

ano 12, no $18-2014$

\author{
Na mesma direção, Thompson em sua obra Costumes em Comum, \\ destaca que uma cultura,
}

\begin{abstract}
é também um conjunto de diferentes recursos, em que há sempre uma troca entre o escrito e o oral, o dominante e o subordinado, a aldeia e a metrópole; é uma arena de elementos conflitivos, que somente sob uma pressão imperiosa - por exemplo o nacionalismo, a consciência de classe, ou a ortodoxia religiosa predominante- assume a forma de um "sistema". E na verdade o próprio termo cultura, com sua invocação confortável de um consenso, pode distrair nossa atenção das contradições sociais e culturais, das fraturas e oposições existentes dentro do conjunto (THOMPSON, 1998, p.17).
\end{abstract}

É claro que não cabem generalizações sobre o termo cultura popular, uma vez que postos numa totalidade homogênea, esvazia-se de sentido e historicidade. Thompson revela assim, que a cultura plebeia em determinado momento histórico, se reveste do 'costume', onde não se auto-definia e nem estava livre de influências externas, assumira sua forma defensivamente para de alguma maneira resistir aos limites e imposições impostos pelos governantes patrícios.

Porém, na realidade, essa cultura se localizava no campo dos valores, significados e atitudes, e, portanto no lugar do imaterial. Sua tentativa foi resgatar a concreticidade do conceito, a cultura popular, e seu lugar no campo material. Para o autor,

a pressão do ser social sobre a consciência social se revela, agora, não tanto por meio da clivagem horizontal base e superestrutura, mas por meio de a) determinação, b) contradição, c) mudança involuntária. Somente em circunstancias excepcionais as pessoas realmente vão além da sua experiência local, de seus valores vividos e apresentam um desafio mais amplo [...] qualquer sistema produtivo conforma as expectativas segundo a linha da menor resistência, visando a conformidade com suas regras (THOMPSON, 2001, p.262) ${ }^{8}$.

\footnotetext{
${ }^{8}$ Esclarece: "por congruências, entendo as regras "necessárias", as expectativas e os valores segundo os quais as pessoas vivem relações produtivas particulares. Não se pode passar a vida
}

TrabalhoNecessário - www.uff.br/trabalhonecessario; Ano 12, № 18/2014. 


\section{Trabalhonecessário}

Issn: 1808 - 799X

ano 12, no $18-2014$

Convém, entretanto, ressaltar que Thompson ainda pensando a experiência, propõe esse resgate entre as relações de produção e a consciência de classe, sua contribuição contraria da mesma forma, tanto concepções reducionistas de causalidade que dissolvem a especificidade histórica, quanto concepções de determinação econômica:

[..] o que interessa a Thompson são as relações do processo em que a as relações de produção -relações de exploração, dominação e apropriação- dão forma a todos os aspectos da vida social em conjunto e o tempo todo, ou exercem pressão sobre eles- a ideia de "simultaneidade" (WOOD, 2010, p. 61).

Em suma, essas primeiras aproximações, pretenderam elucidar o conceito de cultura sem perder de vista o movimento mais amplo do real e sua relação dialética com escalas mais ampliadas da esfera social, levando-se em consideração que esse real é a síntese de múltiplas determinações. Tomada de outras maneiras, pode favorecer formas de produzir e reproduzir estratégias que reforcem a ideia de cultura vinculada aos modelos conservadores dominantes.

Como nos lembra Gramsci, toda hegemonia produz contra-hegemonia, essa totalização não existe apenas passivamente na forma de dominação, mas é um processo, precisa ser continuamente modificada e incentiva assim a ação das classes, oposições e pressões sociais.

protestando; é necessário dissimular e lidar com o status quo. Por contradição, quero dizer, primeiro, o conflito entre o modo de vida e as normas da comunidade local e ocupacional daqueles da "sociedade envolvente". Em segundo lugar, conflito são as maneiras pelas quais o caráter essencialmente explorador das relações produtivas se torna uma experiência vivida, dando origem à manifestação de valores antagonistas e a uma mudança ampla crítica do "senso comum" do poder. Por mudança involuntária me refiro às mudanças ulteriores na tecnologia, demografia e por aí vai, [...] cujas involuntárias repercussões afetam o modo de produção em si, alterando, perceptivelmente, o equilíbrio das relações produtivas" (THOMPSON, 2001 p.262).

TrabalhoNecessário - www.uff.br/trabalhonecessario; Ano 12, № 18/2014. 


\section{Trabalhonecessário}

Issn: 1808 - 799X

ano 12, no $18-2014$

A permanência das lutas no interior da feira nordestina com o objetivo principal de permanecer no local de origem e preservar a cultura popular, é fruto desse movimento de contra-hegemonia. Isso justifica o surgimento do heterogêneo, explica de certa forma a contradição existente ainda que seja representando a imagem do lugar.

Diante disso, o "povo" não está passivo neste processo global, que constitui a visão de mundo de uma sociedade e de uma época, e sim submetido e uma "liderança intelectual e moral" passível de ser contestada.

É nessa chave, que o entendimento acerca da cultura popular dará seguimento à investigações futuras, resgatando a possibilidade de participação do homem simples, de sua experiência e sua cultura, numa direção que configure seu papel enquanto sujeito atuante e partícipe do processo social enquanto arena de disputa de diferentes projetos.

Retomando a contribuição de Gramsci, a luta por uma nova culturamomento da luta por uma nova hegemonia- implica um esforço no sentido de ultrapassar o senso comum e elevá-lo ao nível do bom senso.

\footnotetext{
Nesse sentido, para chegar a uma concepção de mundo mais organizada e sistemática que, liberta de anacronismos e mesclas bizarras, é necessário colocar-se à altura da modernidade e converter-se em instrumento de uma práxis crítica (GRAMSCI apud COUTINHO, 2011, p.84).
}

Nesse sentido, seria necessária uma recomposição cindida entre a alta cultura e a cultura popular, já que para o autor, é lutando por uma nova cultura que se chega a modificar o conteúdo da arte. Essa ideia ajuda a recompor o que poderia num momento anterior ter ficado cindido, e a impulsionar a inter-relação entre esses dois níveis de cultura, apontando para um dinamismo e sem camuflar o conflito de classe.

TrabalhoNecessário - www.uff.br/trabalhonecessario; Ano 12, № 18/2014. 


\section{Trabalhonecessário}

Issn: 1808 - 799X

ano 12, no $18-2014$

A polêmica dos estudos sobre o conceito de cultura popular está na aproximação deste com a noção de senso comum, muitas vezes sem considerar as mediações necessárias para seu entendimento. Na realidade, as noções aqui trabalhadas, pretenderam contribuir para a elucidação dessas questões, destacando alguns autores, que aprofundaram suas análises e elucidaram as experiências de classes subalternizadas- que ao longo da história forjaram formas de resistência e luta a fim de redefinir o lugar da cultura popular e dos trabalhadores.

O caso da Feira de São Cristóvão pode ser observado sob esta ótica na medida em que, como forma de permanência de uma cultura, que tenta preservar suas origens, por um lado, tenta resistir de alguma forma à massificação e às formas de subordinação aos ditames do capital e à indústria cultural. Mas, por outro lado, em que medida essa forma de resistir é consciente, ou, para ir além, em que medida carrega uma proposta alternativa ao que está posto?

TrabalhoNecessário - www.uff.br/trabalhonecessario; Ano 12, № 18/2014. 


\section{Trabalhonecessário}

Issn: 1808 - 799X

ano 12, no $18-2014$

\section{Referências}

CANCLINI, N.G. As culturas populares no Capitalismo. São Paulo: Ed. Brasiliense, 1983.

COUTINHO, Carlos Nelson. Cultura e Sociedade no Brasil: Ensaios sobre ideias e formas. São Paulo: Expressão popular, 2011. 4를.

GRAMSCI, ANTONIO. Cadernos do cárcere, vol. 4, edição de Carlos Nelson Coutinho, com a colaboração de Luiz Sérgio Henriques e Marco Aurélio Nogueira. Rio de Janeiro, Civilização Brasileira, 2001.

MATTOS, Marcelo Badaró. Classes sociais e luta de classes: a atualidade de um debate conceitual. In Revista Em Pauta- teoria social e realidade contemporânea, n. 20, Rio de Janeiro, Ed.UERJ, 2007.

RIBEIRO, Rafaela S. Feira de São Cristóvão: uma incursão sobre os estudos na área e a tentativa de aproximação à relação global-local. Dissertação (Mestrado em Serviço Social), Universidade do Estado do Rio de Janeiro, Rio de Janeiro, 2010.

THOMPSON, E.P. A peculiaridade dos ingleses e outros artigos. Negro, A.L. e Silva, S. (orgs); Campinas: Unicamp, 2001, p. 269-281.

THOMPSON, E.P. A Formação da classe operária inglesa. Rio de Janeiro : Paz e Terra, 2010. V.1.(5 $\left.5^{\mathrm{a}} \mathrm{E}\right)$.

THOMPSON, E.P. Costumes em comum. Estudos sobre a cultura popular tradicional. São Paulo Companhia da Letras, 1998.

WILLIAMS, R. Cultura e Sociedade. Rio de Janeiro: Zahar, 1992.

WILLIAMS, R. Cultura. São Paulo, Paz e Terra, 2011.

WILLIAMS, R. Cultura e materialismo. São Paulo, Ed Unesp, 2011a. 


\section{Trabalhonecessário}

Issn: $1808-799 X$

ano 12, no $18-2014$

WOOD, Ellen. Democracia contra capitalismo. A renovação do materialismo histórico. São Paulo: Boitempo, 2010.

Recebido em maio de 2014 Aprovado em junho de 2014 